\title{
Cytokine Responses to LTP Induction in the Rat Hippocampus: A Comparison of In Vitro and In Vivo Techniques
}

\author{
Joanna L. Jankowsky, ${ }^{1,3}$ Brian E. Derrick, ${ }^{2}$ and Paul H. Patterson ${ }^{1,4}$ \\ ${ }^{1}$ Division of Biology, California Institute of Technology, Pasadena, California 91125, USA; ${ }^{2}$ Cajal Neuroscience Research Center, Division of Life \\ Sciences, University of Texas, San Antonio, Texas 78249, USA
}

\begin{abstract}
Because exogenous application of a number of cytokines and growth factors can alter synaptic properties, we sought to determine if endogenous cytokine expression is affected by neuronal activity. In addition, we examined whether cytokine expression is altered by the techniques used to stimulate and record from hippocampal neurons. Using semi-quantitative RNase protection and RT-PCR assays, we studied the expression of 18 cytokine, growth factor, and receptor genes in the hippocampus following the induction of Schaffer collateral-CA1 long-term potentiation (LTP). We found that various cytokines are dramatically induced following preparation of slices for in vitro recording and as a result of injury following acute electrode placement in vivo. These increases can be overcome in vivo, however, using permanent electrodes implanted three weeks prior to testing. Using this chronic preparation, we found that interleukin-6 (IL-6) mRNA was upregulated nearly 20 -fold by LTP induction in vivo, marking the first demonstration of endogenous regulation of this cytokine in response to LTP. In situ hybridization for IL-6 revealed that upregulation is tightly localized near the site of stimulation and is detected only in non-neuronal cells, identified as GFAP+ astrocytes and GFAP- cells within proximal blood vessels. Coupled with previous results showing that exogenously applied IL-6 can prevent the induction of LTP, this finding suggests a mechanism by which the local release of a cytokine could regulate LTP at nearby sites.
\end{abstract}

A variety of intercellular signaling proteins have recently been shown to modulate hippocampal long-term potentiation (LTP). Some of the best-studied examples of such factors are the neurotrophins, particularly brain-derived neurotrophic factor (BDNF). Our primary interest, however, was in a group of functionally related proteins, the cytokines. These proteins can affect many of the same neuronal properties as the neurotrophins, including gene expression, differentiation, survival, and axonal sprouting (Loughlin and Fallon 1993; Patterson 1995; Gadient and Otten 1997; Mattson et al. 1997; Murphy et al. 1997). Despite these similarities, the role of cytokines at the synapse has not been thoroughly explored. Cytokine expression can be upregulated in response to the overt neuronal activity induced by seizure (Minami et al. 1991; Morgan et al. 1993; Andreasson and Worley 1995; Bruce et al. 1996; Inokuchi et al. 1996; Lai et al. 1996; Tretter et al. 1996; Gahring et al. 1997; Jankowsky and Patterson 1999), and upregulation of a few cytokines following LTP has also been observed (Andreasson and Worley 1995; Inokuchi et al. 1996; Schneider et al.

${ }^{3}$ Present address: Division of Neuropathology, Johns Hopkins University School of Medicine, Baltimore, MD 21205 ${ }^{4}$ Corresponding author.

E-MAIL php@caltech.edu; FAX 626-585-8743.

Article and publication are at www.learnmem.org/cgi/doi/ $10.1101 / \mathrm{lm} .32600$.
1998). In addition, work from several groups has demonstrated that exogenous application of certain cytokines can affect synaptic transmission and LTP (for review see Jankowsky and Patterson 2000). Together, these findings suggest parallels to the well-studied roles of neurotrophins at the synapse. Unlike the small number of neurotrophins, however, there are over 40 identified cytokines, many of which are found in the CNS (Benveniste 1992; Sei et al. 1995; Mire-Sluis and Thorpe 1998), although only a handful have been examined in the context of LTP. We therefore took a broad approach to identifying the potential involvement of cytokines in synaptic transmission by looking for expression changes in a wide array of cytokines and their receptors following induction of LTP in several hippocampal preparations.

Recognizing that cytokines are known to function in neural injury, where they may act to mediate communication between cells of the nervous and immune systems, it was also important to look carefully for cytokine perturbations caused by the techniques used to study synaptic activity. All preparations used to study LTP require some form of mechanical intervention, either slicing the hippocampus for in vitro experiments or inserting electrodes in vivo, each of which could cause injury-induced cytokine changes.

In the present study, we tested the hypothesis that one or more cytokine proteins may have a role in activity-regu-

LEARNING \& MEMORY 7:400-412 @ 2000 by Cold Spring Harbor Laboratory Press ISSN1072-0502/00 \$5.00

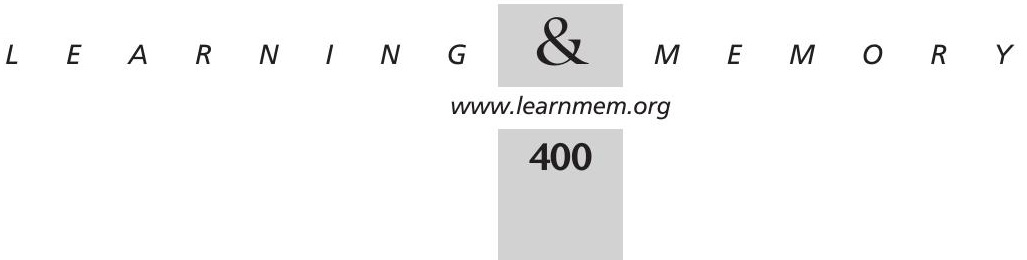


lated modifications at the Schaffer collateral-CA1 synapse. We started with a broad-based screen for alterations in the expression of 18 cytokine, growth factor, and receptor genes by semi-quantitative RNAse protection and RT-PCR assays before and after LTP induction in this pathway, both in vivo and in vitro. Initial experiments demonstrated that the mechanical damage caused by two common electrophysiological preparations, hippocampal slices and acute in vivo recording, can alter the expression of specific cytokines. Therefore, to separate the effects of neural injury from those induced by synaptic activity, we utilized a chronic in vivo preparation in which electrode implantation (and consequent injury) was temporally separated from the electrical stimulation. Using this chronic preparation, we described changes in expression of two genes that are affected by synaptic activity in the absence of injury. We further localized and identified the cell types responsible for increased mRNA expression of one of these factors, interleukin-6 (IL-6), and suggested a mechanism by which release of this factor in the temporally and spatially restricted pattern we observed could regulate the ability of nearby neurons to respond to subsequent input.

\section{RESULTS}

\section{Cytokine Expression in Hippocampal Slices}

While our initial goal was to identify cytokines and growth factors whose expression is altered by LTP induction, we first had to examine the effects of mechanical damage required for in vitro recording. Because cytokine expression is known to be altered in many models of neural injury, it was important to establish what effects cutting slices for in vitro experiments may have on cytokine levels. Using semiquantitative RNase protection and RT-PCR assays, we compared cytokine mRNA levels from intact, freshly dissected hippocampus to mRNA levels from slice tissue. The latter tissue had been cut for in vitro recording, allowed to recover in an air-interface chamber for at least $90 \mathrm{~min}$, then held (without electrodes) in the recording chamber for the duration of an LTP experiment. Seventeen mRNAs were assayed, including neuropoietic cytokines (LIF and CNTF; IL-6 was not assayed in slices), neuropoietic receptor subunits (gp130, CNTF-R, LIF-R, and IL-6-R), TGF $\beta$ superfamily members (BMP2, BMP6, TGF $\beta 1$, TGF $\beta 2$, activin $\beta$ A, activin $\beta B$, and inhibin $\alpha$ ), hematopoietic cytokines (IL- $1 \alpha$, IL-1 $\beta$, and IL-1RA), and the neurotrophin BDNF. Of the 17 mRNAs examined, seven were altered by the manipulations needed to prepare the hippocampus for in vitro recording (Fig. 1A). Three cytokines (IL-1 $\alpha$, IL-1 $\beta$, and LIF) were upregulated two- to fourfold by slice preparation, while four others (IL-1RA, BMP6, TGF 32 , and CNTF) were downregulated compared to the intact hippocampus. Thus, cutting hippocampal slices for in vitro experiments alters the expression of certain cytokines, even before electrophysiology is attempted.

Once the change in basal cytokine expression caused by slice preparation was determined, we asked if expression of any of these cytokines was further altered by the induction of LTP. Two control groups, naive slices described above and LFS slices that received low frequency stimulation but no tetanus, were used to look for expression changes following induction of LTP in a third set of slices. Comparison of the mRNA levels in the naive and LFS control slices to levels in slice tissue $1 \mathrm{~h}$ after the induction of LTP revealed no further differences in any of the cytokines tested (Fig. 1B). The absence of stimulation-associated expression changes may have been due to the short time interval examined, which may not have been long enough to allow alterations in these mRNAs to develop, or to the masking effects of injury, which may have occluded effects of electrical stimulation.

During the course of this study, Schneider et al. (1998) published experiments describing the upregulation of IL- $\beta$ mRNA following LTP in vitro. In their system, they found that IL-1 $\beta$ levels were immediately elevated after slice preparation, and that only after prolonged recovery could LTP effectively up-regulate IL-1 $\beta$ levels. Because this was a critical point in their experiments, and LTP did not generate the same increase in IL-1 $\beta$ in our system, we wanted to know if IL-1 $\beta$ was similarly regulated by our method of slice preparation. Under our conditions, we found instead that IL-1 $\beta$ expression increased steadily with time after slice preparation. If we set the value for IL-1 $\beta$ expression in the intact hippocampus at 1.00 , then immediately after cutting slices, the relative level of IL-1 $\beta$ expression was largely unchanged $(0.90 \pm 0.16[\mathrm{SEM}])$. Expression increased slightly to $1.17 \pm 0.152 \mathrm{~h}$ after slice preparation; at $4.5 \mathrm{~h}$, expression rose to $2.44 \pm 0.34$. By the latest time point examined, IL-1 $\beta$ expression in slices held $7 \mathrm{~h}$ in vitro was more than fourfold initial values $(4.12 \pm 0.17)$. The differences between our results and those of Schneider et al. (1998) may be explained by several technical differences between the studies. First, we used younger animals (6-7 weeks vs. 8-10 weeks). Second, we used a slightly different ACSF formulation. Third, the slices were incubated in different recovery chambers (air-interface vs. immersion). Fourth, the temperature at which the slices were held for recovery was substantially different $\left(22^{\circ}-25^{\circ} \mathrm{C}\right.$ vs. $\left.33^{\circ}-35^{\circ} \mathrm{C}\right)$.

\section{Cytokine Expression in the Acute In Vivo Preparation}

Believing that cytokine alterations due to the tissue injury required for in vitro recording may have masked effects of electrical stimulation, we next moved to an acute in vivo preparation, which eliminates the mechanical damage of cutting slices. Additionally, in vivo recording allows examination of a longer time course following LTP than is prac-

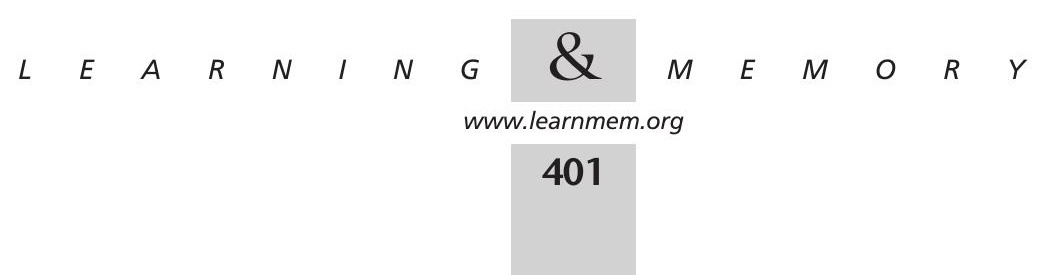


A

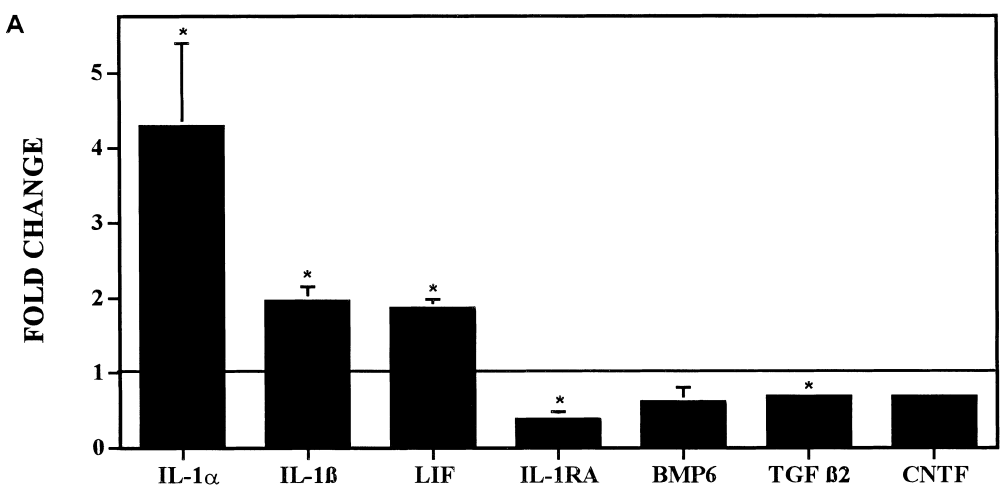

B

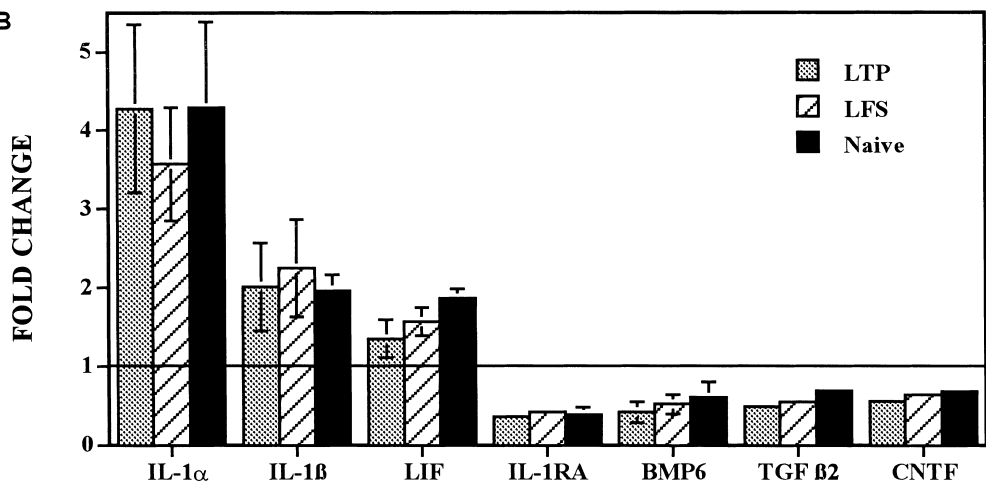

Figure 1 Expression of several cytokines is affected by cutting slices for in vitro experiments, and synaptic activity does not further alter cytokine levels. $(A)$ Expression of seven cytokines is altered by the tissue damage caused by making slices. Cytokine expression in naive slices (without electrodes) is normalized to the levels of basal expression in the intact hippocampus. Several cytokines are upregulated by the tissue preparation (*: IL-1 $\alpha$, IL-1 $\beta$, LIF, $p<0.05$, Student's $t$-test), while four cytokines (IL-1RA, BMP6, TGF $\beta 2$, and CNTF) are lower in the slice tissue than in the intact hippocampus (*: IL-1RA, TGF $\beta 2, p<0.05$, Student's $t$-test). (B) Cytokine expression is not further altered by electrical stimulation. Data from $A$, showing alterations in mRNA levels produced by slice preparation, are shown again for comparison in this figure (naive slices, black bars). No significant differences were observed between experimental conditions (LFS, striped bars; LTP, gray bars), raising the possibility that cytokine alterations due to injury may be masking effects due to synaptic activity.

tical with hippocampal slices. Again, two control groups, naive animals without electrodes and "LFS" animals in which electrodes were inserted and only low frequency stimulation was given, were used to evaluate cytokine mRNA changes following LTP induction. Surprisingly, of the 18 mRNAs examined, including the 17 factors tested in vitro plus IL-6, expression of seven genes was significantly altered simply by the placement of electrodes into the hippocampus. Activin $\beta A$, BDNF, LIF, IL-6, IL-1 $\alpha$, IL-1RA, and IL-1 $\beta$ were all substantially upregulated by electrode insertion and delivery of only the LFS test stimuli (Fig. 2). Because of the overwhelming effects of injury, as in the slice experiments, we again observed no further changes in cytokine expression following the induction of LTP in the acute in vivo preparation (data not shown). The extreme changes in cytokine expression in vivo following electrode placement could, however, be substantially attenuated by modifying the electrode insertion procedure. Using a much slower placement technique in which each electrode was inserted only once, and approximately $10 \mathrm{~min}$ were allowed for the cells to recover/reseal between the placement of each electrode, cytokine induction could be substantially reduced, although not entirely eliminated (Fig. 2).

\section{Cytokine Expression in the Chronic In Vivo Preparation}

To completely isolate acute effects caused by electrode injury from the synaptic activity we sought to study, we utilized a chronic in vivo preparation in which electrophysiology is performed three weeks after electrode implantation. This allows sufficient time for injury-induced cytokine levels to return to basal levels before testing changes due to synaptic activity. LTP is induced in the chronically-implanted animals (Fig. 3) by the same stimulation protocol used in the acute preparation, and attains the same degree of potentiation. We again used naive and LFS controls for evaluation of changes associated with LTP. In addition, we included a third control group; sham animals were implanted with electrodes but received no electrical stimulation, not even the LFS test stimuli, and so were true controls for injury due to electrode insertion. Because we had previously determined that expression of most cytokines initially screened was not altered by injury or LTP, only those seven cytokines affected by electrode injury (possibly masking effects due to synaptic activity) in the acute experiments were examined. Assessment of cytokine expression in the sham control animals following the three week recovery period revealed that expression of all seven cytokines had returned to basal levels, and were equivalent to unoperated controls. Thus the chronic preparation allowed us to look for changes specific to evoked synaptic activity. Of the mRNAs assayed (LIF, activin $\beta A$, IL-6, IL-1 $\alpha$, IL-1 $\beta$, IL-1RA, and BDNF), we identified two, BDNF and IL-6, that were altered by electrical stimulation. Surprisingly, we found that in the Schaffer-collateral pathway, in vivo expression of BDNF mRNA decreased following LFS. If we set BDNF expression in naive animals to 1.00, then, expression after low frequency stimulation was significantly reduced to roughly $40 \%$ of initial levels $(0.38 \pm$ $0.08, p<0.01$, Student's $t$-test). Induction of LTP returned

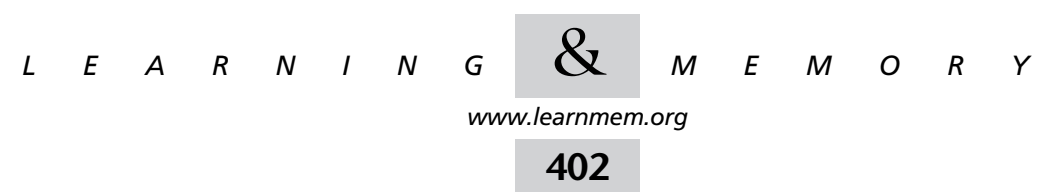




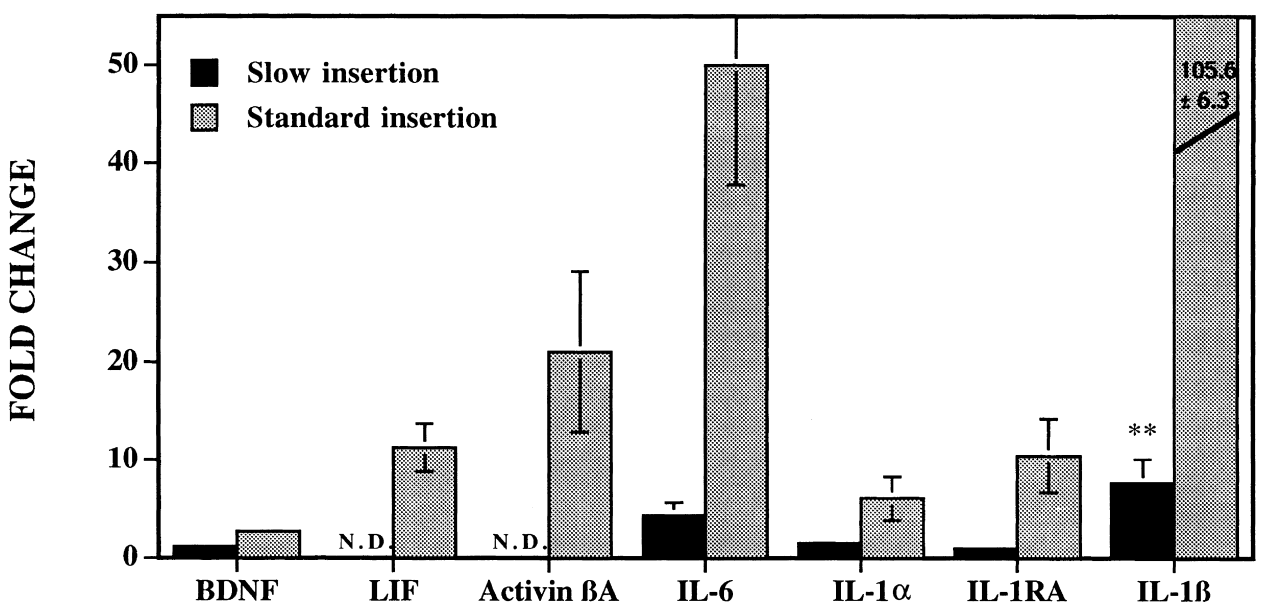

Figure 2 Electrode insertion causes cytokine induction in vivo. The gray bars show the upregulation of several cytokines and growth factors by tissue damage associated with placing electrodes into the hippocampus for acute recording. All animals received low-frequency test stimulation, but no tetanic stimulus. Values for all cytokines shown are statistically different from basal expression in the naive, uninjured hippocampus, and are shown as fold-change from basal values (BDNF, LIF, activin $\beta$ A, IL-6, IL- $1 \alpha$, IL-1RA: $p<0.05$; IL-1 $\beta$ : $p<0.01)$. The black bars show that, in all cases examined, cytokine upregulation can be attenuated by a single, slow electrode placement (N.D.: LIF and activin $\beta$ A not determined). Expression of IL-1 $\beta$ is significantly reduced by this technique compared to standard electrode insertion (**: $p<0.01)$.

BDNF expression to control levels, but caused no further upregulation $(0.90 \pm 0.03)$.

Much more dramatic was the effect on IL-6 mRNA expression; this cytokine increased nearly 20-fold with the induction of LTP (Fig. 4). Unlike BDNF, we found no significant changes in IL-6 levels in any of the control groups; IL-6 expression was altered solely by LTP induction. One animal was excluded from the calculations of mean and significance shown in Figure 4; this animal was an additional naive control that was added to the experiment several months after the other animals had been sacrificed. The extremely high level of expression seen in this animal was inconsistent with the remaining nine control animals (naive, sham, and LFS), and may have been due to a difference in age or in housing conditions used after the other animals were removed.

\section{Localization of IL-6 Upregulation Following LTP Induction}

The localization and identity of cells upregulating IL-6 expression after LTP in chronically implanted animals was determined by combined in situ hybridization and immunohistochemistry. Brains were removed $4 \mathrm{~h}$ after the induction of LTP and sectioned through the septotemporal extent of both hippocampi. In parallel, brains from two control conditions, LFS and sham-operated animals, were also examined. Hybridization conditions were chosen so that basal IL-6 expression present in naive control animals was not detected, allowing ready visualization of upregulation in response to experimental manipulation (i.e., LTP induction).
Under these conditions no IL-6 hybridization was detected in the LFS or sham brains, while increased IL-6 expression was observed in tissue from each of four animals in which LTP had been induced. Moreover, IL-6 + cells were detected only in the hippocampus ipsilateral to the electrodes.

Three features of IL-6 expression in the potentiated hippocampi were striking. First, as shown in Figure 5A, IL-6+ cells were tightly restricted to the area immediately surrounding the site of stimulation. This restriction was reflected in both the area of expression within a given section and in the number of sections that contained positive cells. Second, a very small number of cells expressed detectable (i.e., substantially increased) levels of IL-6 after LTP. Even the most intensely stained sections contained $>50$ IL- $6+$ cells. The apparent discrepancy between the small number of IL-6+ cells observed following LTP by in situ hybridization and the large (more than 20-fold) increase in IL-6 mRNA expression measured by RT-PCR may be explained by technical limitations of in situ hybridization. Detection by in situ hybridization likely requires that the level of target mRNA within the cell surpasses a concentration threshold. Because basal expression of IL-6 in the hippocampus is very low, even a large upregulation does not bring IL-6 expression to high levels. It is possible that many cells upregulate IL-6 expression following LTP induction, but only a subset of those reach the threshold required for in situ detection. A trade-off between sensitivity and specificity is commonly encountered using in situ hybridization for low abundance transcripts; Schneider et al. (1998) experienced similar discrepancies between RT-PCR and in situ detection in their study of hippocampal IL-1 $\beta$.

The third feature of note was the identity of the cells upregulating IL-6 expression. In no case examined did neurons within the pyramidal cell layer display increased IL-6 signal. Instead, IL-6+ cells were either glial fibrillary acidic protein (GFAP) + astrocytes in the parenchyma or GFAPcells within local blood vessels (Fig. 5 B,C). Vessel-associated IL-6 expression was found only near the site of stimulation; as shown in Figure 5A, vessels within the same section, but located further from the electrodes, contained no IL-6+ cells. As shown in Figure 5B, IL-6+ cells are located

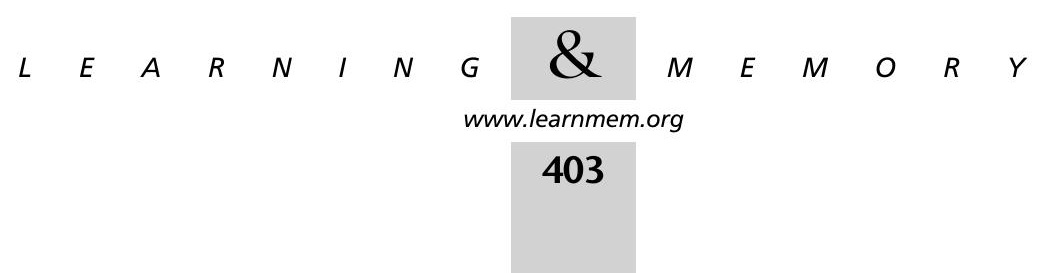




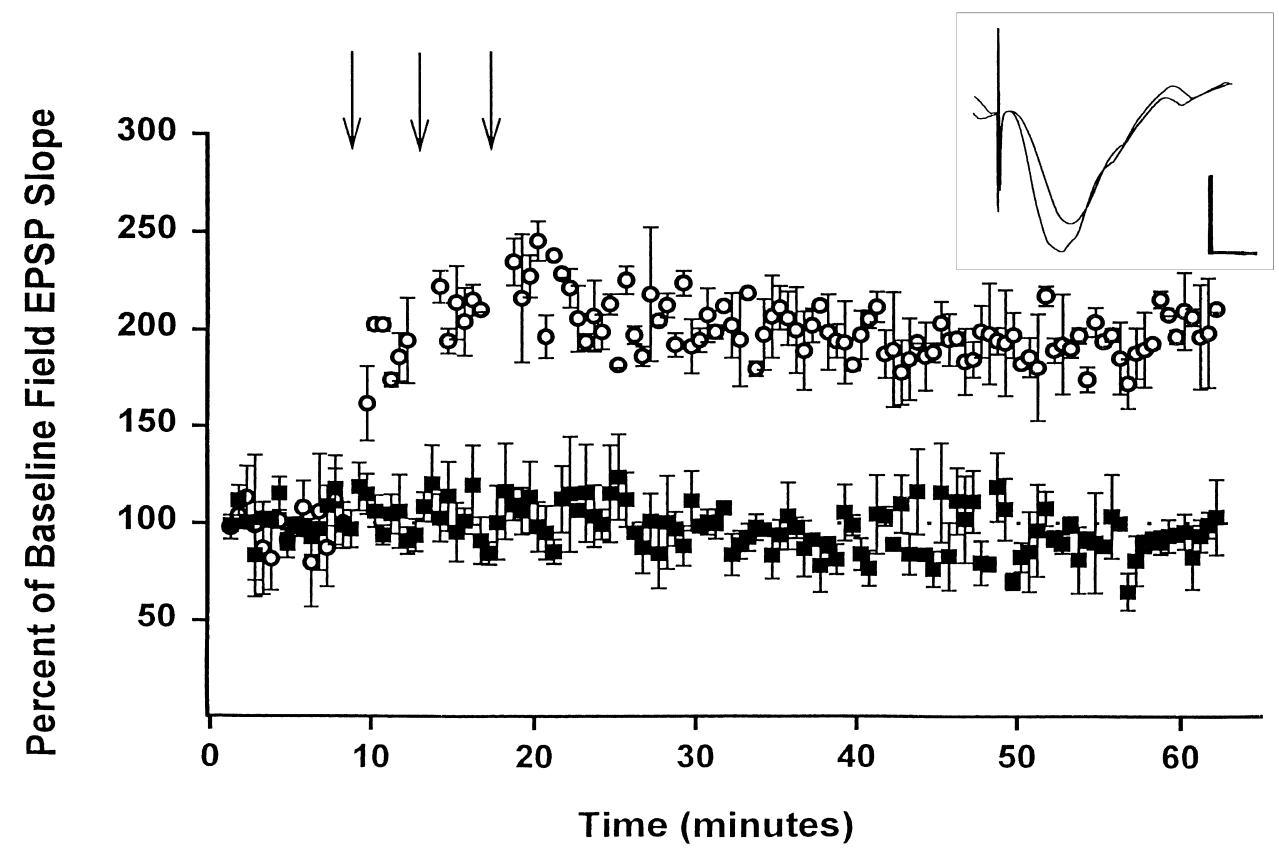

Figure 3 Long-term potentiation of Schaffer collateral-CA1 responses in animals with chronically implanted electrodes. Point plot of field EPSP slope values in animals in which LTP was induced (open circles) by $100 \mathrm{~Hz}, 1 \mathrm{~s}$ high frequency trains delivered at 5 min intervals (arrows) or in which only low frequency stimulation was given (closed squares). The inset shows Schaffer -CA1 responses prior to tetanization (upper trace) and a potentiated response $1 \mathrm{~h}$ after LTP induction (lower trace). Potentiated responses recorded following tetanic stimulation in hippocampal slices and in acutely implanted animals attained similar increases in field EPSP slope compared to pre-tetanic responses $(163 \pm 1.47 \%$ and $183 \pm$ 18\% (SEM), respectively). Scale bars: $1 \mathrm{mV}, 5 \mathrm{~ms}$.

both at the borders and in the lumen of the blood vessel, suggesting that this population may be comprised of both endothelial cells of the vessel wall and adherent white blood cells recruited from the circulation. While only one of

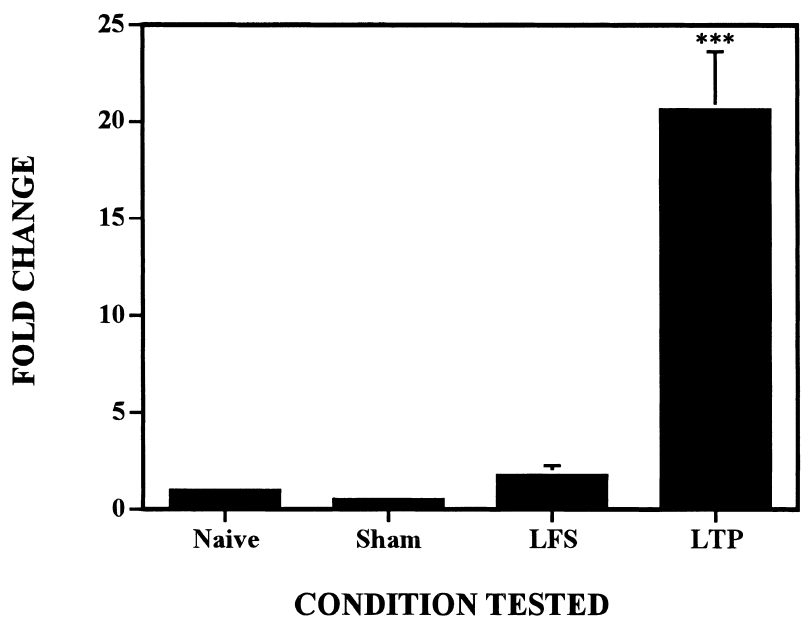

Figure 4 Expression of IL-6 is strongly and specifically induced by LTP. Levels of IL-6 mRNA in sham, LFS, and LTP groups are shown normalized to basal values in the naive controls. Four hours after induction of LTP, IL-6 mRNA was significantly increased compared to naive controls ${ }^{* * *}$ : $P<0.005$, Student's $t$-test). the four LTP brains examined had both glial- and vessel-associated IL-6+ cells (shown in Fig. 5); each of the other three brains examined showed elevated IL-6 expression in cells of either one cell type or the other.

For comparison, we studied the localization of IL-6 upregulation in another, more intense model of synaptic activity, pilocarpine-induced seizure. Results from this model added support to our identification of IL- $6+$ cells in the potentiated hippocampus. Initial RT-PCR experiments demonstrated that within 2 to 4 $\mathrm{h}$ of pilocarpine injection and subsequent generalized status epilepticus, hippocampal IL-6 expression was increased up to tenfold over basal levels (data not shown). In situ hybridization $6 \mathrm{~h}$ after pilocarpine injection revealed that IL- 6 expression was still substantially elevated in the hippocampus, and was also detected in other brain areas. Staining for GFAP produced a pattern of double- and single-labeled cells similar in many respects to that seen in the potentiated hippocampus. After seizure, as after LTP, IL-6+/GFAP+ astrocytes were present in the hippocampus (Fig. 6A), although IL-6+ astrocytes comprised a smaller percentage of the total IL- $6+$ cells after seizure than after LTP. In addition, IL-6+/GFAP- cells associated with blood vessels, similar to those observed after LTP (Fig. 5B), were also seen after seizure (Fig. 6B). IL-6+ cells were located both at the borders and within the lumen of the vessels, suggesting again that these IL-6+ cells are vascular endothelial cells and/or adherent white blood cells from the circulation. Unlike the highly localized pattern of IL-6 expression induced by LTP, seizure-induced upregulation occurs throughout the brain, and vessels with IL-6+ cells are seen in the hippocampus, thalamus, and cortex (data not shown). The broad distribution of IL-6 expression after seizure correlates well with the spread of neuronal hyperactivity incurred during generalized seizures, in stark contrast to the very localized changes in synaptic responses that were induced following LTP.

\section{DISCUSSION}

We examined the effects of synaptic activity on the expres-

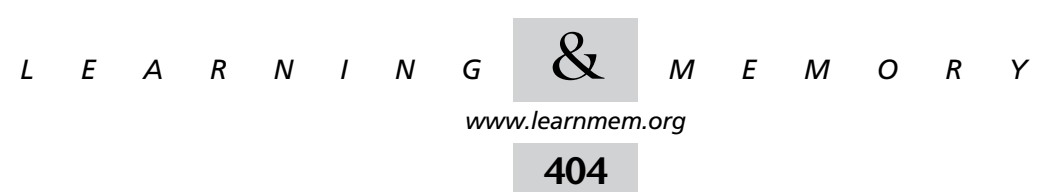




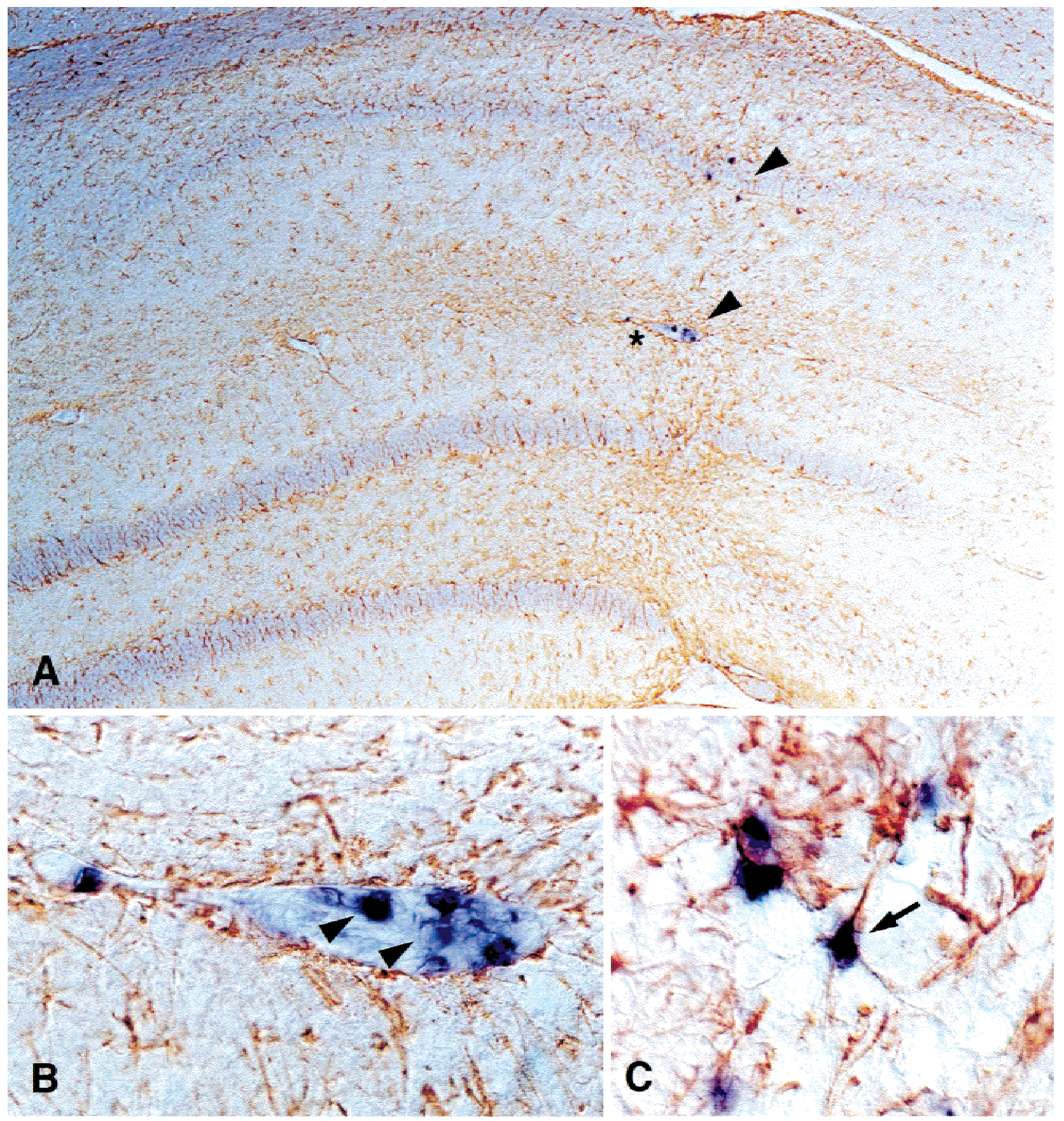

Figure 5 Localization of IL-6 expression in the hippocampus after LTP induction in chronically-implanted animals. (A) In situ hybridization for IL-6 in hippocampal sections ipsilateral to the stimulating electrode reveals highly localized mRNA upregulation in a small subset of non-neuronal cells near the electrode sites. Arrowheads indicate representative IL-6+ cells in blue. Conditions used for in situ hybridization do not reveal basal IL-6 expression, which can be detected in the hippocampus by RT-PCR. Immunostaining for GFAP in brown identifies a subset of IL-6+ cells as GFAP+ astrocytes, as well as a second population of IL-6+/GFAP- cells located within a nearby blood vessel (asterisk). (B) High-magnification enlargement of the blood vessel shown in A. GFAP co-staining of neighboring astrocytes reveals that these IL-6+ cells are both part of and apparently inside of the blood vessel wall, suggesting that they are vascular endothelial cells and/or adherent white blood cells. (C) High magnification photomicrograph of an IL-6+/GFAP+ astrocyte, indicated by an arrow, from the section adjacent to that shown in $A$.

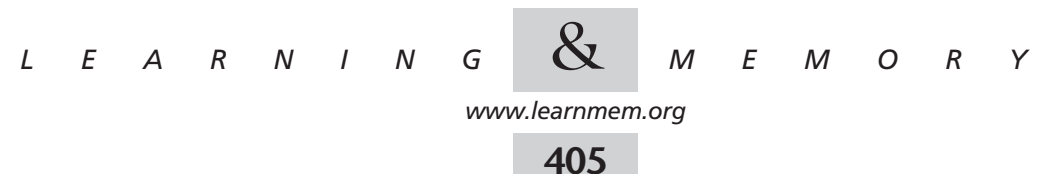




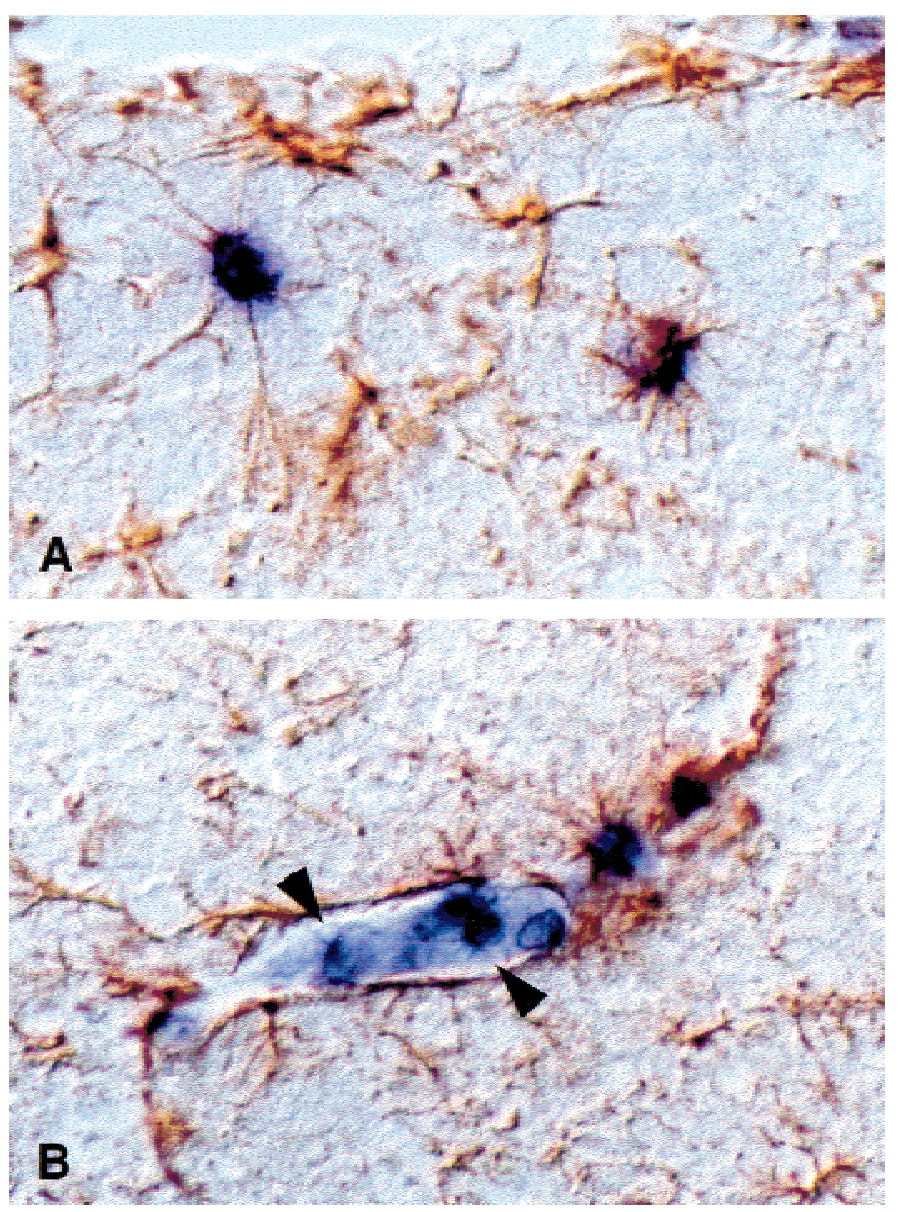

Figure 6 Seizure induces IL- 6 expression in cell types similar to those affected by LTP. (A) Six hours after the injection of pilocarpine to induce generalized seizures, a small number of IL- $6+$ (blue)/GFAP+ (brown) astrocytes are seen in the hippocampus. (B) The majority of IL- $6+$ cells are not co-labeled for GFAP, and are found associated with blood vessels in the thalamus, cortex, and hippocampus. Arrowheads indicate IL-6+/ GFAP- cells as both part of and inside this blood vessel in the thalamus, as had been seen in blood vessels of the hippocampus following LTP induction (Figure $5[A]$ and $[B]$ ).

sion of 18 growth factors, cytokines, and receptors, and identified two that were specifically affected by electrical stimulation. While one of these, BDNF, had been previously studied, expression of the cytokine IL- 6 had not yet been examined in this context. Because exogenous application of IL-6 can affect synaptic properties (Li et al. 1997), upregulation of this cytokine by synaptic activity, combined with its restricted spatial pattern of expression, suggests an interesting way in which local synaptic plasticity may be regulated, as discussed in more detail below. Identification of these two factors required that we employ one of the most technically challenging preparations for studying hippocampal LTP, using electrodes that are chronically implanted into the Schaffer collateral pathway in order to separate the effects of stimulation from the injury associated with elec- trode insertion. While attempting to address the question of activity-induced cytokine regulation in more commonly used acute preparations, we also observed significant changes in cytokine expression caused by the tissue damage associated with both slice electrophysiology and acute in vivo recording. Because several of these cytokines are known to affect synaptic properties (reviewed in Jankowsky and Patterson 2000), these results indicate that the conditions under which LTP is induced in acute preparations may be quite different than what is found in the unperturbed brain.

Few studies have examined the effects of mechanical damage to the hippocampus caused by making slices for in vitro recording (Kirov et al. 1999). While neurons largely recover a normal resting potential and retain the ability to respond to electrical stimulation with an intensity-appropriate output, our results indicate the possibility of artifactual alteration in synaptic properties in vitro. For example, IL-1 $\beta$, which has been shown to inhibit the induction of LTP when applied exogenously (Katsuki et al. 1990; Bellinger et al. 1993; Cunningham et al. 1996), was upregulated in our hippocampal slices. During the course of this work, Schneider et al. (1998) described an immediate upregulation of IL-1 $\beta$ induced by cutting slices for in vitro experiments, which subsided with prolonged recovery time. In our studies, however, IL-1 $\beta$ expression steadily increased with time after slicing. Several technical differences may account for this discrepancy, as outlined in the Results section. In either case, mRNA levels for this and other potentially synapticmodulating factors are significantly different than those found in the intact brain, and may affect the synaptic properties being measured in the slice preparation.

Because cytokine induction due to mechanical damage in hippocampal slices may have masked effects of LTP on cytokine expression, we also studied LTP in the intact hippocampus. Surprisingly, both LFS and LTP animals displayed large increases in the expression of several cytokines, indicating that injury caused by electrode insertion was responsible for cytokine changes in the acute in vivo preparation. Moreover, although some of the same genes were upregulated in vivo as in the slices, the induction reached far greater levels in the intact animal. This difference could be due to the infiltration of blood cells with high cytokine expression into the injury site in vivo; such cells would not be present in the isolated slice. Alternatively, the dramatic response in vivo might be due to signaling through synaptic connections with other areas of the brain that also would not be present in the isolated slice.

Again, few studies have examined the potential injury caused by electrode insertion. The most closely related experiments are studies of cortical stab wounds, usually induced with a scalpel. The tissue damage caused by stab wound would likely be much more extensive than the dam

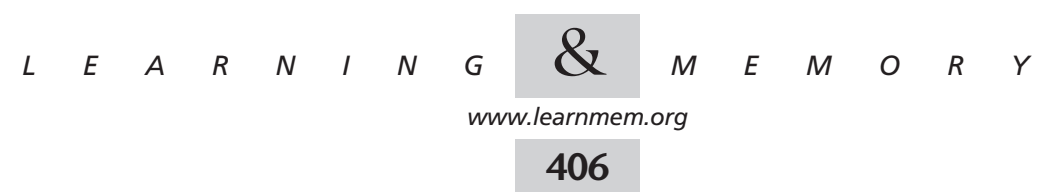


age caused by insertion of fine electrodes. Nonetheless, some of the same cytokines respond to both forms of injury. For example, LIF mRNA is increased more than tenfold $4 \mathrm{~h}$ after electrode insertion in the hippocampus, a response similar to the upregulation seen after scalpel-induced injury to the cortex (Banner et al. 1997). Importantly, several of the factors we found upregulated by electrode insertion (including IL-1 $\beta$, IL-6, and BDNF) are able to alter synaptic properties when exogenously applied to hippocampal preparations (Katsuki et al. 1990; Bellinger et al. 1993; Kang and Schuman 1995; Cunningham et al. 1996; Li et al. 1997; Schneider et al. 1998).

We found that the chronic in vivo preparation, in which a three-week recovery period separated electrode implantation from electrophysiology, eliminated the confounding effects of injury from the study of synaptic activity. Compared to levels in the intact hippocampus, all seven cytokine mRNAs assayed (each of which was significantly induced by acute electrode insertion) returned to basal levels following a three week recovery. Of these seven, two (BDNF and IL-6) were specifically affected by synaptic activity. Several earlier studies have described BDNF upregulation in vivo following induction of LTP by stimulation of the perforant path (Castren et al. 1993; Dragunow et al. 1993; Bramham et al. 1996). Stimulating a different pathway, we found that BDNF was instead downregulated by LFS, and that LTP induction returned expression to basal levels. That our results differ from those of previous studies could be due to several factors. Prior studies induced LTP in the perforant path while we examined LTP in the Schaffer collateral pathway. Moreover, earlier studies used awake, behaving animals while we used anesthetized animals. Our choices were based on the desire to retain the same pathway and stimulation paradigm used in our hippocampal slice and acute in vivo experiments. These methodological differences may also explain why we did not see upregulation of activin $\beta \mathrm{A}$ or IL-1 $\beta$, both of which had previously been reported to follow LTP induction in the perforant path of awake behaving animals (Andreasson and Worley 1995; Schneider et al. 1998). Further study of these divergent results could shed light on alternative mechanisms used in the two synaptic populations studied or on distinctions between awake and anesthetized neuronal function.

More dramatic was our finding that IL- 6 mRNA expression, when temporally isolated from the effects of injury in the chronic preparation, was increased more than 20-fold by the induction of LTP. Using in situ hybridization, we described a novel, non-neuronal cytokine upregulation following hippocampal LTP. Increased IL-6 mRNA was detected in a limited number of both GFAP+ astrocytes and GFAP- vascular cells that were restricted to the site of stimulation. Although not found in the potentiated neurons themselves, IL-6 expression was spatially limited to cells near the stimulation site, within both the distal dendritic regions and surrounding the CA1 pyramidal cell layer. Thus cells showing the greatest extent of IL-6 upregulation were localized to regions where the greatest number of pyramidal cells were stimulated, suggesting that the glial IL-6 response may result from the concerted activation of a large number of primary neurons. Activity-induced communication between hippocampal neurons and glia is not without precedent (Vernadakis 1996; Araque et al. 1999). Experiments in acute and organotypic hippocampal slices have demonstrated that neuronal stimulation elevates calcium levels in local astrocytes (Araque et al. 1999). In turn, pharmacological manipulation of hippocampal astrocytes can affect the physiology of nearby neurons (Araque et al. 1999). Thus, the communication between stimulated neurons and local non-neuronal cells may well be a two-way dialog.

Our observation of IL-6 upregulation in cells within local blood vessels suggests a third partner in this conversation. Based on the distribution of IL- 6 mRNA in the vessels, both endothelial cells of the vessel wall and circulating white blood cells may be responding to LTP induction. This is especially intriguing given that neither of these cell types is in direct contact with the potentiated neurons. IL-6 upregulation in these cells may thus result from indirect cues, possibly soluble factors released from the stimulated neurons or signals received from the astrocytes that surround the vessel wall to form the blood brain barrier. Alternatively, IL-6 upregulation may result from direct depolarization by the high frequency stimulus used to induce LTP. In any case, this observation suggests that a stimulation paradigm commonly used as a model of learning and memory may result in participation of cell types not often considered in non-pathological neuronal physiology. This phenomenon is not unfounded, however. Studies in adult doves have demonstrated the recruitment of circulating mast cells to specific brain nuclei within hours of certain stereotyped behaviors (Silver et al. 1996; Yang et al. 1999). It will be of great interest to understand more fully the potential for vascular cells, possibly both endothelial and hematopoietic, to influence neuronal activity and plasticity.

The LTP-induced upregulation of IL- 6 takes on additional interest in light of the ability of exogenous IL- 6 to prevent potentiation of the Schaffer collateral pathway, without affecting previously established LTP (Li et al. 1997). If IL-6 protein is also upregulated by LTP induction, it is possible that increased synthesis and later release of this cytokine by local glia could inhibit subsequent potentiation at nearby synapses. Activity-induced IL-6 upregulation and release might then provide a mechanism for the potentiated synapse to indirectly curtail enhancement at neighboring synapses. Normalization of neurons and stabilization of their networks may thus be accomplished by the release of a signal that is correlated with activity, and that can act at nearby sites in the network (Turrigiano 1999). In this con-

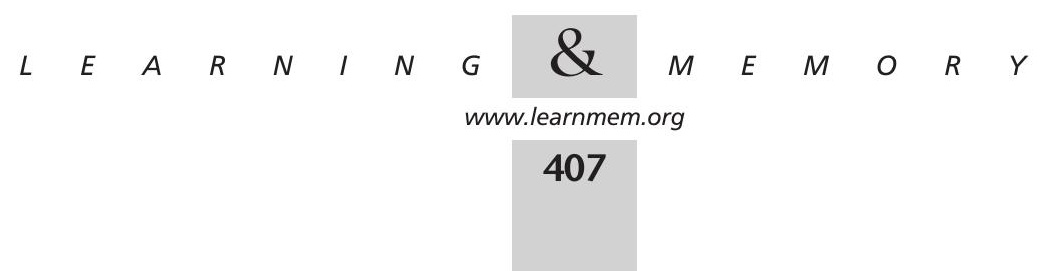


text, the increase in IL- 6 mRNA, and potentially IL- 6 protein, after tetanic stimulation would limit the number of synapses changed on a given neuron, or prevent further alterations in synaptic strength in regions that have undergone recent modifications. Future experiments using mice in which the gene for IL-6 has been disrupted may shed more light on the role of this cytokine in hippocampal synaptic plasticity.

\section{METHODS}

\section{Hippocampal Slice Electrophysiology}

Young adult (6-7 wk old), male Sprague-Dawley rats (Simonsen Laboratories) were anesthetized with Halothane and killed by decapitation. The brain was quickly removed, placed in ice-cold, oxygenated artificial cerebrospinal fluid (ACSF: $119 \mathrm{mM} \mathrm{NaCl}, 2.5 \mathrm{mM}$ $\mathrm{KCl}, 1.3 \mathrm{mM} \mathrm{MgSO} 4,2.5 \mathrm{mM} \mathrm{CaCl}, 1.0 \mathrm{mM} \mathrm{NaH2PO} 4,26.2 \mathrm{mM}$ $\mathrm{NaHCO} 3,11.0 \mathrm{mM}$ glucose), and both hippocampi dissected out. Transverse slices, $450 \mu \mathrm{m}$ thick, were prepared with a tissue chopper and were allowed to recover for at least $1.5 \mathrm{~h}$ at room temperature $\left(22^{\circ}-25^{\circ} \mathrm{C}\right)$ in a humidified, oxygenated chamber, suspended over a dish of ACSF, prior to use for electrophysiology. Slices were then transferred to a recording chamber where they were submerged in a stream of ACSF maintained at room temperature $\left(22 \%{ }^{\circ}-25^{\circ} \mathrm{C}\right)$ and perfused with $95 \% \mathrm{O}_{2} / 5 \% \mathrm{CO}_{2}$. Three slices were used in the recording chamber at one time. One slice was placed at the back of the recording chamber with no electrodes and was used as a control for the effects of tissue preparation (naive). Bipolar tungsten stimulating and glass capillary recording electrodes were placed in the stratum radiatum layer of area CA1 in each of the two remaining slices. Field EPSPs were evoked by stimulation of the Schaffer collateral-commissural afferents once every $30 \mathrm{~s}$ and the initial (1-2 ms) slope was measured. Baseline responses were recorded for at least $20 \mathrm{~min}$ prior to induction of LTP by tetanic stimulation (four individual $100 \mathrm{~Hz}$ trains delivered for $1 \mathrm{~s}$ each at the test intensity with an intertrain interval of $15 \mathrm{~s}$ ) in one of the two recorded slices (LTP); the other slice received only the continued low-frequency test stimuli to control for effects of electrophysiological recording (LFS). Field responses were measured for $1 \mathrm{~h}$ after applying the tetanus; percent baseline values were determined from the final $10 \mathrm{~min}$ interval recorded. Only those sets of slices in which the percent baseline (\%BL) of the LTP slice was over $130 \%$, and the \%BL of the LFS slice was between $90 \%$ and $110 \%$, were used for mRNA analysis.

\section{In Vivo Hippocampal Electrophysiology}

All studies used adult male Sprague-Dawley rats (Charles River, NC) weighing 350-375 g. Animals were housed in pairs, with food and water available ad libitum, and maintained on a $12 \mathrm{~h}$ light: $12 \mathrm{~h}$ dark cycle, in accordance with NIH guidelines.

For studies involving both acute and chronic electrode implantation, animals were anesthetized with pentobarbital $(50 \mathrm{mg} /$ $\mathrm{kg}$ i.p.) and given booster pentobarbital injections $(25 \mathrm{mg} / \mathrm{kg}$, i.p.) at 30-45 min intervals to maintain a surgical level of anesthesia. Body temperature was maintained at $37^{\circ} \mathrm{C}$ with a heating pad. Following mounting of the head in a stereotaxic frame, all surgical procedures were performed under sterile conditions. Holes were drilled in the skull above the right hemisphere with a sterile drill bit, and the overlying dura was punctured with a needle.

Bipolar stimulating electrodes, made from twisted Teflon- coated, stainless steel wire (0.008 in outside diameter) exposed only at the tip (tip separation approximately $0.10 \mathrm{~mm}$ ), were used to deliver current to the Schaffer collaterals. Constant current stimulation (100-500 $\mu \mathrm{A}$ biphasic pulses, $0.1 \mathrm{~ms}$ duration each phase) was provided by a Grass (Braintree, MA) stimulus isolation unit. The recording electrode, a single Teflon-coated wire exposed only at the tip, was placed in the stratum radiatum approximately $200 \mu \mathrm{m}$ below the CA1 pyramidal layer of the dorsal hippocampus (AP $-3.5 \mathrm{~mm}$, ML $3.0 \mathrm{~mm}$, DV $2.3 \mathrm{~mm}$ from top of brain) (Paxinos and Watson 1982). The stimulating electrode was placed about 0.5 $\mathrm{mm}$ posterior to the recording electrode, and slightly medial to the recording site (AP $-4.0 \mathrm{~mm}$, ML $2.8 \mathrm{~mm}$, DV $2.53 \mathrm{~mm}$ from top of brain). This corresponds with the orientation of stratum radiatum fibers in the intact brain (Rawlins and Green 1977). Extracellular recordings were referenced to an indifferent site (a screw mounted on the anterior skull).

In the acute studies, responses were collected and LTP was induced shortly (30-60 min) after surgical electrode implantation $(n=7)$. In studies involving permanent electrode implantation (Barnes 1979), electrode wires were attached to gold Amphenol pins (Newark Electronics), mounted in 9 pin Malino/MacIntyre (Science Technology Centre, Carleton University, Ottawa, Canada) sockets, and affixed to the skull with dental acrylic ( $n=10$ total implanted; three of these were used for LTP induction, seven for LFS and sham controls, as described below) Animals were given a single dose of antibiotic (Bicillin, 100,000 units i.m.) and oral analgesic (Ibuprofen) for a period of three days following surgery. Animals were allowed to recover for three weeks prior to recording.

In both acute surgical studies and studies using animals with permanently implanted electrodes, animals were anesthetized with pentobarbital prior to evoking responses. Anesthesia was necessary in animals with permanent electrodes because our preliminary studies revealed that the stimulation parameters used to induce non-decremental Schaffer-CA1 LTP (1 s $100 \mathrm{~Hz}$ trains) frequently elicited seizures and "wet dog" shakes in awake animals. The results reported here are very different from those we obtained in a study of the cytokine response to seizure (Jankowsky and Patterson 1999), verifying that seizure-like activity was not evoked in the present study. Once fully anesthetized, responses were evoked using a current intensity eliciting a response that was $50 \%$ of the amplitude (baseline to peak) of the maximally-evokable response (as determined by asymptotic amplitudes using current intensities ranging from 10 to $500 \mu \mathrm{A}$ ). This $50 \%$ current intensity was used to evoke $0.05 \mathrm{~Hz}$ responses and induction of LTP with high-frequency stimulation. The magnitude of the field EPSP response was measured by the EPSP slope (mV/ms) occurring between 1 and $3 \mathrm{~ms}$ after response onset (Experimenter's Workbench software, DataWave Technologies). Responses were collected at a rate of $0.05 \mathrm{~Hz}$ for a 15-20 min period. LTP was induced by delivery of three $1 \mathrm{~s}$ trains of $100 \mathrm{~Hz}$ stimulation (100 pulses), with an intertrain interval of $5 \mathrm{~min}$. These parameters were found to be optimal for induction of non-decremental LTP in area CA1 (Frey et al. 1993). Following delivery of the trains, responses were collected every $20 \mathrm{~s}$ for $1 \mathrm{~h}$. All evoked responses were amplified on a Grass P3 series A.C. preamplifier, filtered at $0.1 \mathrm{~Hz}-10 \mathrm{kHz}$, digitized $(10 \mathrm{kHz})$, and stored for off line analysis. Stimulation-induced changes in evoked responses (LTP) were measured by comparing slopes of responses evoked during the $5 \mathrm{~min}$ period prior to tetanization with the slopes of responses evoked between 55 and 60 min post-tetanus.

Two control groups were included for acute surgical LTP studies: low-frequency stimulation (LFS) and naive. LFS animals underwent surgery, electrode insertion, and $0.05 \mathrm{~Hz}$ stimulation, but

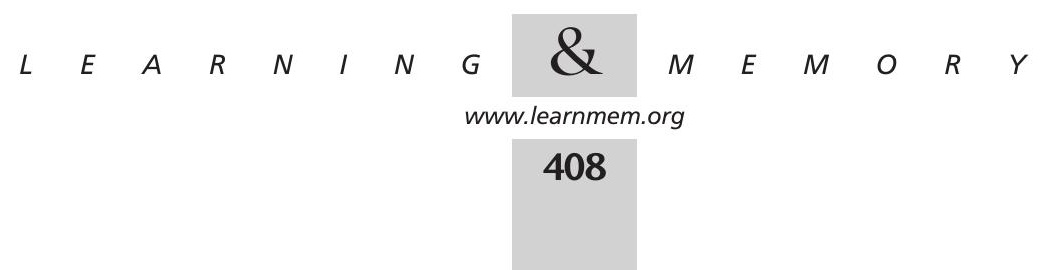


received no tetanic stimulation $(n=7)$. An additional set of LFS animals was used to test the effects of a more slow and careful electrode placement technique on cytokine induction in the acute preparation $(n=2)$. Electrodes in these animals were inserted only once, and a 10 min recovery period was allowed between placement of each electrode. As with other LFS controls, these animals received $0.05 \mathrm{~Hz}$ stimulation, but no tetanic stimulation. The naive controls had no surgery $(n=10)$. Because of the limited amount of tissue recovered from each animal and the large number of cytokines assayed, not all animals were assessed for expression of each cytokine tested.

Studies involving permanent electrode implantation included three control groups: LFS $(n=3)$, naive $(n=4)$, and sham-operated animals $(n=3)$ that underwent surgery and permanent electrode placement, but received no electrical stimulation. Our initial naive cohort included only three animals; two were housed together, one alone. During the course of this study, evidence that isolation stress could affect levels of IL-1 $\beta$ was published (Murray and Lynch 1998); we then added one additional control animal that was singly housed for a time equivalent to the duration of a chronic LTP experiment.

\section{RNA Isolation}

Four hours after the induction of LTP in vivo (both acute and chronic preparations), animals were euthanized by sodium pentobarbital overdose and decapitated. The brain was quickly removed, and the right hippocampus was isolated. The area of electrode impalement was identified from small blood marks left by electrode insertion; the hippocampus was trimmed to a $3 \mathrm{~mm}$ block composed of tissue $1.5 \mathrm{~mm}$ to each side (rostral/caudal) of the electrode tracks. This hippocampal piece was further cut into three transverse slices (to aid in later dentate gyrus removal) before being quickly frozen in pre-chilled isopentane.

Hippocampal slices used for in vitro electrophysiology were harvested and quickly frozen on dry ice $1 \mathrm{~h}$ after tetanus was delivered to one of the three slices in the recording chamber.

All hippocampal tissue (in vitro and in vivo) was stored at $-80^{\circ} \mathrm{C}$ until use. On the day of RNA isolation, each slice was thawed individually in $500 \mu \mathrm{L}$ of phosphate buffered saline (PBS) containing $10 \mathrm{mM}$ vanadyl ribonucleoside complex (Gibco BRL) as an RNAse inhibitor. The dentate gyrus and remaining parts of the fimbria-fornix and entorhinal cortex were dissected away, and the isolated CA3-CA1 fragment was transferred to Solution D (Chomczynski and Sacchi 1987) and homogenized. Each animal used for in vivo electrophysiology was analyzed individually, while RNA from hippocampal slice tissue was extracted from groups of ten slices to obtain enough RNA for multiple assays. The distribution of individual slices into four groups (ten experiments each) was balanced so that the average $\% \mathrm{BL}$ in the LTP slices $(163 \pm 1.47 \%)$ and the average time of recovery before use for electrophysiology (4.01 $\pm 0.01 \mathrm{~h}$ ) was equal in each group. Because of the large number of cytokines assayed and the relatively small amount of RNA recovered from each slice group, not all cytokines were measured in each set of slices.

Hippocampal slices not used for electrophysiology were collected after various recovery times in the air-interface chamber $(0$, $2,4.5$, and $7 \mathrm{~h}$ after slice preparation). The tissue was quickly frozen on dry ice and stored at $-80^{\circ} \mathrm{C}$ until use. Four slices from each time point were pooled for RNA extraction; two sample pools were collected for each point. In order to allow direct comparison of cytokine responses in our slice preparation to results previously published for IL-1 $\beta$ (Schneider et al. 1998), the dentate gyrus was not removed from this tissue prior to RNA extraction.

Additional hippocampal tissue was collected intact (without slicing or electrophysiological manipulation) to determine basal cytokine expression in the adult rat brain. The dentate gyrus was not removed from this tissue before RNA extraction.

Total RNA was extracted from both the isolated CA1-CA3 and the intact hippocampal tissue by a modification of the acid-phenol method (Chomczynski and Sacchi 1987), and stored at $-80^{\circ} \mathrm{C}$ until use.

\section{RNAse Protection Assay (RPA)}

Plasmids containing portions of ciliary neurotrophic factor (CNTF), transforming growth factor $\beta 1$ (TGF $\beta 1$ ), transforming growth factor $\beta 2$ (TGF $\beta 2$ ), bone morphogenetic protein 6 (BMP6), interleukin-1 $\beta$ (IL-1 $\beta$ ), and interleukin-1 receptor antagonist (IL-1RA) were cloned by PCR from sciatic nerve cDNA (CNTF) or adult rat brain cDNA (TGF $\beta 1$, TGF $\beta 2$, BMP6, IL-1 $\beta$, IL-1RA). Polymerase chain reaction fragments were ligated into either pCRII (Invitrogen) or Bluescript (Stratagene) vectors and sequenced to confirm their identities. Rat IL-6 cDNA was purchased from ATCC (Rockville, MD). Additional rat cDNAs were gifts from several laboratories: CNTF receptor (CNTFR) clone pSK-rCNTFR(5'-PST1) from Dr. Samuel Davis and Dr. George Yancopolous, Regeneron Pharmaceuticals, Tarrytown, NY; IL-6 receptor (IL-6R) (pSPT19 clone) from Dr. Reto Gadient and Dr. Uwe Otten, University of Basel, Switzerland; BMP2 from Dr. Jian Feng, University of Texas, San Antonio; activin $\beta A$, activin $\beta B$ and inhibin $\alpha$ from Dr. Ming-Ji Fann (Fann and Patterson 1995); and leukemia inhibitory factor (LIF) receptor (LIFR) from Dr. Lisa Banner (Banner and Patterson 1994). The LIF clone was previously described in this laboratory (Yamamori et al. 1989). The housekeeping gene, glyceraldehyde phosphate dehydrogenase (GAPDH), used as an internal control with each cytokine or receptor RPA reaction was provided by Dr. Lisa Banner (Banner and Patterson 1994). The RPA was performed as described (Patterson and Fann 1992), using approximately $5 \mu \mathrm{g}$ total RNA per reaction. Briefly, plasmids were linearized and ${ }^{32} \mathrm{P}$-labeled antisense probes generated by in vitro transcription were hybridized to hippocampal total RNA. After overnight hybridization at $55^{\circ} \mathrm{C}$, reactions were digested with RNAse A and RNAse T1. Digestion was stopped with proteinase $\mathrm{K}$ and RNA extracted with phenol-chloroform. Reaction products were separated on denaturing $6 \%$ polyacrylamide gels to yield protected fragments of 266 nucleotides for CNTF, 294 nucleotides for IL-6R, 589 nucleotides for IL-1 $\beta, 222$ nucleotides for IL-1RA, 430 nucleotides for CNTFR, 245 nucleotides for BMP2, 311 nucleotides for BMP6, 406 nucleotides for TGF $\beta 1$, 252 nucleotides for TGFß2, 299 nucleotides for LIFR, 450 nucleotides for GP130, 386 nucleotides for inhibin $\alpha, 348$ nucleotides for activin $\beta \mathrm{A}, 267$ nucleotides for activin $\beta \mathrm{B}, 169$ nucleotides for LIF, and 133 nucleotides for GAPDH. Radioactivity was measured by scanning the protected fragments on a Phosphorimager 445SI (Molecular Dynamics) and quantitated with ImageQuant software. The intensity of the protected fragment for each cytokine or receptor was compared to the intensity of the protected fragment of GAPDH in that reaction and the ratio was expressed in arbitrary units. Quantitation of GAPDH mRNA levels across experimental conditions revealed that the GAPDH mRNA levels were not altered significantly by electrophysiological manipulation. Determination of statistical significance between conditions was performed by the two sample Student's $t$-test, assuming equal variances (two-tailed $P$ value).

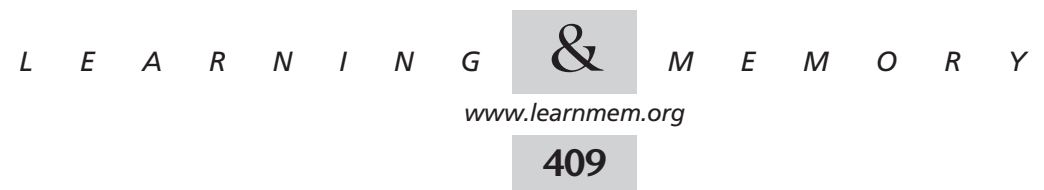




\section{Reverse-Transcription Polymerase Chain Reaction (RT-PCR)}

The basal levels of interleukin 1- $\alpha$ (IL-1 $\alpha$ ) and IL- 6 mRNAs were too low to detect by RPA, requiring the more sensitive RT-PCR assay to measure changes induced by electrophysiological manipulation. Brain-derived neurotrophic factor (BDNF) was also assayed as a possible positive control: BDNF was shown to be induced by LTP both in vivo and in vitro, although under slightly different conditions than in our experiments (Patterson et al. 1992; Castren et al. 1993; Dragunow et al. 1993; Bramham et al. 1996). Hippocampal RNA was treated with 1 unit of heat-labile DNAse (Gibco BRL), after which Superscript II reverse transcriptase (Gibco BRL) was used to generate cDNA pools with random hexamers. IL- $1 \alpha$, IL- 6 , BDNF, and the internal control GAPDH were then amplified by PCR from these libraries. Primer sets, listed $5^{\prime}-3^{\prime}$, used to amplify specific gene products were: IL-1 $\alpha: 5^{\prime}$ TCC TGA CTT GTT TGA AGA CC, $3^{\prime}$ CTT AGC CGT CTC TTC TTC AG; IL-6: 5' TGT TCT CAG GGA GAT CTT GG, 3' TCC AGG TAG AAA CGG AAC TC (Pitossi and Besedovsky, 1996); BDNF: 5' ATG ACC ATC CTT TTC CTT ACT ATG GT, $3^{\prime}$ TCT TCC CCT TTT AAT GGT CAG TGT AC (Zaheer et al. 1995); GAPDH: 5' ACC ACC ATG GAG AAG GCT GG, 3' CTC AGT GTA GCC CAG GAT GC (Brown et al. 1994). Amplification reactions were performed in a final volume of $100 \mu \mathrm{L}$, consisting of 10 $\mu \mathrm{L}$ of diluted cDNA, 1 unit of Taq polymerase (Promega), $1 \times$ PCR buffer (Promega), $2.5 \mathrm{mM} \mathrm{MgCl}_{2}$ (except IL-6: $1.5 \mathrm{mM}$ ), $0.2 \mathrm{mM}$ of each dNTP, and one set of primers (200 ng each). The cycle programs used to amplify each gene were: IL-1 $\alpha$, IL-6, and BDNF: $94^{\circ} \mathrm{C}$ for $5 \mathrm{~min}, 58^{\circ} \mathrm{C}$ for $85 \mathrm{~s}, 72^{\circ} \mathrm{C}$ for $1 \mathrm{~min}(75 \mathrm{~s}$ for BDNF) $1 \times$, followed by 39 cycles of $94^{\circ} \mathrm{C}$ for $30 \mathrm{~s}, 58^{\circ} \mathrm{C}$ for $85 \mathrm{~s}$, and $72^{\circ} \mathrm{C}$ for $30 \mathrm{~s}$ ( $75 \mathrm{~s}$ for BDNF); GAPDH: $94^{\circ} \mathrm{C}$ for $5 \mathrm{~min}, 60^{\circ} \mathrm{C}$ for $85 \mathrm{~s}$, and $72^{\circ} \mathrm{C}$ for $1 \mathrm{~min} 1 \times$, followed by 27 cycles of $94^{\circ} \mathrm{C}$ for $30 \mathrm{~s}, 60^{\circ} \mathrm{C}$ for $85 \mathrm{~s}$, and $72^{\circ} \mathrm{C}$ for $45 \mathrm{~s}$. To follow the amplification rate of each reaction and identify the linear range, PCR reactions were stopped every four cycles starting at 24 cycles (IL- $1 \alpha$, IL-6, and BDNF) or 12 cycles (GAPDH), and $5 \mu \mathrm{L}$ aliquots were removed.

\section{cDNA Hybridization}

Dilutions of each PCR cycle sampled were dot-blotted onto Nytran $0.2 \mu \mathrm{m}$ nylon membrane (Schleicher \& Schuell) for Southern hybridization. Prior to hybridization with radiolabeled probes, membranes were prehybridized for $2 \mathrm{~h}$ at $42^{\circ} \mathrm{C}$ in a solution of $6 \times$ SSPE, $1 \%$ SDS, $10 \times$ Denhardt's solution, $20 \mu \mathrm{g} / \mathrm{mL}$ tRNA, and $50 \mu \mathrm{g} / \mathrm{mL}$ herring sperm DNA. Oligonucleotide probes designed to bind the PCR products internal to the amplification primers were end-labeled with ${ }^{32} \mathrm{P}$ using polynucleotide kinase (Boehringer Mannheim). Oligonucleotide probes were tested for specificity by hybridization against end-stage PCR reactions run out on agarose gels and transferred to nylon membrane. Internal oligonucleotide sequences, listed 5' -3', were: GAPDH: ATC GTG GAA GGG CTC ATG ACC ACA GTC CAT; IL-1 $\alpha$ : TAC AGT TCT GCC ATT GAC CAT CTG TCT CTG; IL-6: CAG CGA TGA TGC ACT GTC AGA AAA CAA TCT G; BDNF: TGG GTC ACA GCG GCA GAT AAA AAG ACT GCA. After $2 \mathrm{~h}$, prehybridization buffer was removed and replaced with $6 \times \mathrm{SSPE} / 1 \%$ SDS containing $500 \mathrm{kcpm} / \mathrm{mL}$ of labeled probe. Hybridization was continued for an additional $14-16 \mathrm{~h}$ at $65^{\circ} \mathrm{C}$. Membranes were then washed three times for $10 \mathrm{~min}$ each in $6 \times \mathrm{SSPE} /$ $1 \%$ SDS at room temperature, followed by a final wash in $1 \times \mathrm{SSPE} /$ $1 \%$ SDS for $3 \mathrm{~min}$ at $65^{\circ} \mathrm{C}$.

\section{Quantitation of RT-PCR Reactions}

Bound radioactivity was quantitated with a Phosphorimager 445SI using ImageQuant software. Using samples taken from regular intervals in the PCR amplification, a linear range was determined for each reaction. Over many trials, we found that the amount of PCR product generated by 28 cycles fell in the linear range for the IL- $1 \alpha$, IL- 6 and BDNF reactions, while GAPDH reached linear values by 16 cycles. In order to control for variations in cDNA synthesis between reactions, values for $\mathrm{IL}-1 \alpha, \mathrm{IL}-6$, and BDNF expression, taken as the intensity of hybridization of each reaction at 28 cycles, were expressed as a ratio to GAPDH expression amplified 16 cycles from the same initial cDNA pool. Values for cytokine expression based on this ratio were expressed in arbitrary units, and statistical significance between conditions assessed by Student's $t$-test.

\section{Seizure Induction}

Adult male Sprague-Dawley rats (200-250 g; Simonsen Laboratories) were pretreated by injection of atropine sulfate $(1 \mathrm{mg} / \mathrm{kg}$, i.p., Phoenix Pharmaceutical) $20 \mathrm{~min}$ prior to induction of status epilepticus by injection of pilocarpine hydrochloride $(310-320 \mathrm{mg} / \mathrm{kg}$, i.p., Sigma; Turski et al. 1983). The time of pilocarpine injection was used as the reference point. Seizures were monitored behaviorally; most animals developed seizures characterized by salivation, forelimb clonus, and rearing before entering a state of continuous stage III/IV seizures according to the classification of Racine (Racine 1972) that characterize status epilepticus. Seizures were terminated with diazepam (10-12 mg/kg, i.p., Steris Laboratories) $4 \mathrm{~h}$ after the injection of pilocarpine. Following termination of seizures, all animals were hydrated with lactated Ringer's solution $(5-10 \mathrm{~mL} / \mathrm{kg} / \mathrm{h}$, s.c.; Abbott Laboratories). Only animals that displayed continuous convulsive seizure activity were used for these experiments. Six $\mathrm{h}$ after the injection of pilocarpine, animals were sacrificed by decapitation and brains removed into prechilled isopentane for in situ analysis.

\section{In Situ Hybridization}

Digoxigenin-labeled sense and antisense cRNA in situ probes were transcribed from a rat IL-6 cDNA clone (ATCC) using the Megascript in vitro transcription kit (Ambion). Following transcription, both sense and antisense probes were hydrolyzed to an average length of 200-300 nucleotides before use in hybridization.

Animals (LTP: $n=4$; LFS: $n=2$; sham: $n=2$; pilocarpine-induced seizure: $n=2$ ) were given an anesthetic overdose and killed by decapitation $4 \mathrm{~h}$ after tetanic stimulation (LTP, LFS, and sham) or $6 \mathrm{~h}$ after injection of pilocarpine (seizure). Brains were removed and immediately frozen in pre-chilled isopentane. After embedding in Cryo-M-Bed (Bright, Huntingdon, UK), $20 \mu \mathrm{m}$ frozen sagittal (LTP, LFS, and sham) or coronal (pilocarpine-induced seizure) sections through the septotemporal extent of the hippocampus were collected on Superfrost Plus slides (Fisher Scientific). Before use, sections were fixed with $4 \%$ paraformaldehyde for $20 \mathrm{~min}$ before digestion with $50 \mu \mathrm{g} / \mathrm{mL}$ Proteinase $\mathrm{K}$ in Tris-EDTA buffer $(50 \mathrm{mM}$ Tris $\mathrm{pH} 7.5,5 \mathrm{mM}$ EDTA) for $10 \mathrm{~min}$ at room temperature. Sections were then acetylated with acetic anhydride, and prehybridized at $60^{\circ} \mathrm{C}$ for $4 \mathrm{~h}$ in hybridization buffer $(50 \%$ formamide, $5 \times \mathrm{SSC}, 50$ $\mu \mathrm{g} / \mathrm{mL}$ tRNA, $100 \mu \mathrm{g} / \mathrm{mL}$ heparin, $1 \times$ Denhardt's solution, $0.1 \%$ Tween-20, 0.1\% CHAPS, $5 \mathrm{mM}$ EDTA). This solution was replaced with hybridization buffer containing $1 \mu \mathrm{g} / \mathrm{mL}$ of digoxigenin-labeled RNA probe, and hybridization continued for an additional $14-18 \mathrm{~h}$ at $60^{\circ} \mathrm{C}$. Following hybridization, the sections were washed several times in $0.2 \times \mathrm{SSC}$ at $60^{\circ} \mathrm{C}$, followed by two changes of PBS with $0.1 \%$ Triton-X and $2 \mathrm{mg} / \mathrm{ml} \mathrm{BSA} \mathrm{(PBT)} \mathrm{at} \mathrm{room}$ temperature. Sections were next blocked with $20 \%$ sheep serum

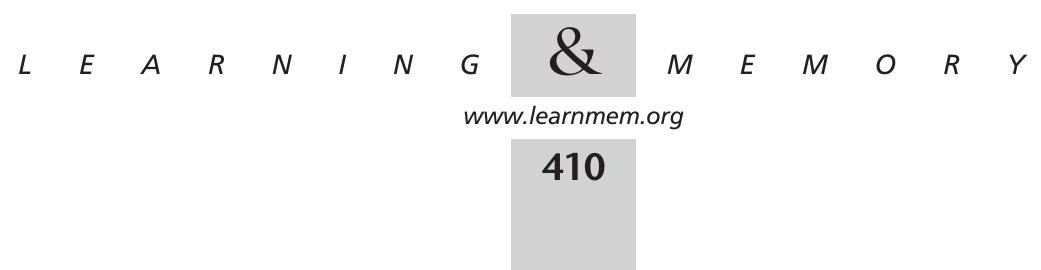


and 2\% Blocking Reagent (Boehringer Mannheim) for several hours at room temperature. The blocking solution was replaced with anti-digoxigenin antibody (Boehringer Mannheim) diluted 1:2000 in blocking solution and the sections were incubated overnight at $4^{\circ} \mathrm{C}$. After several $30 \mathrm{~min}$ washes with PBT, staining was visualized with nitroblue tetrazolium and 5-bromo-4-chloro-3-indolyl phosphate (Boehringer Mannheim).

\section{Immunohistochemistry}

Following in situ hybridization, sections were rinsed several times with PBS and refixed in $4 \%$ paraformaldehyde for $20 \mathrm{~min}$ at room temperature before endogenous peroxidase activity was quenched with $0.3 \%$ hydrogen peroxide in PBS for $30 \mathrm{~min}$. Slides were blocked with several changes of $5 \%$ goat serum in PBS with $0.1 \%$ Triton-X. After blocking, slides were incubated overnight at $4{ }^{\circ} \mathrm{C}$ with anti-GFAP antibody diluted 1:500 in blocking solution (GFAP antibody: rabbit anti-cow polyclonal 1:500, Accurate Chemical and Scientific Corp.). Sections were washed several times with blocking solution, followed by incubation for $1 \mathrm{~h}$ with secondary antibody conjugated to horseradish peroxidase diluted 1:200 in blocking solution (goat anti-mouse polyclonal, Chemicon). Following several washes with Tris-Imidazole buffer (TI: $50 \mathrm{mM}$ Tris, $\mathrm{pH} 7.5$, $20 \mathrm{mM}$ Imidazole, $0.1 \%$ Triton-X), the peroxidase reaction product was developed with $0.04 \%$ diaminobenzidene (Sigma) in TI buffer.

\section{ACKNOWLEDGMENTS}

The authors thank Erin Schuman and members of the Schuman lab, especially Hannah Dvorak, Gerald Reis, Lixin Tang, and David Kantor, for help with in vitro electrophysiology. We acknowledge Rachel Grimes, Desiree Villarreal, and Cyndy Davis for technical assistance with in vivo experiments. We are also grateful to Lisa Banner, Herman Govan, and Kai Zinn for tireless advice on establishing the RNA assays, and to Doreen McDowell, Bill Lease, and Jesse Flores for continued laboratory support. We thank Erin Schuman and Andy Groves for helpful comments on the manuscript. This work was supported by NIH (National Institutes of Health) grants NS20916 to P.H.P., GM08194 to B.E.D., DA11983 to B.E.D., and by National Research Service Award training grant 5 T32 GM 07737 (J.L.J.).

The publication costs of this article were defrayed in part by payment of page charges. This article must therefore be hereby marked "advertisement" in accordance with 18 USC section 1734 solely to indicate this fact.

\section{REFERENCES}

Andreasson, K. and Worley, P.F. 1995. Induction of $\beta$-A activin expression by synaptic activity and during neocortical development. Neuroscience 69: 781-796.

Araque, A., Parpura, V., Sanzgiri, R.P., and Haydon, P.G. 1999. Tripartite synapses: Glia, the unacknowledged partner. Trends Neurosci. 22: 208-215.

Banner, L.R., Moayeri, N.N., and Patterson, P.H. 1997. Leukemia inhibitory factor is expressed in astrocytes following cortical injury. Exp. Neurol. 147: 1-9.

Banner, L.R. and Patterson, P.H. 1994. Major changes in the expression of the mRNAs for cholinergic differentiation factor/leukemia inhibitory factor and its receptor after injury to adult peripheral nerves and ganglia. Proc. Natl. Acad. Sci. 91: 7109-7113.

Barnes, C.A. 1979. Memory deficits associated with senescence: A neurophysiological and behavioral study in the rat. J. Comp. Physiol. Psychol. 93: 74-104.

Bellinger, F.P., Madamba, S., and Siggins, G.R. 1993. Interleukin $1 \beta$ inhibits synaptic strength and long-term potentiation in the rat CA1 hippocampus. Brain Res. 628: 227-234.

Benveniste, E.N. 1992. Inflammatory cytokines within the central nervous system: Sources, function, and mechanism of action. Am. J. Physiol. 263: C1-C16.

Bramham, C.R., Southard, T., Sarvey, J.M., Herkenham, M., and Brady, L.S 1996. Unilateral LTP triggers bilateral increases in hippocampal neurotrophin and trk receptor mRNA expression in behaving rats: Evidence for interhemispheric communication. J. Comp. Neurol. 368: 371-382.

Brown, M.A., Metcalf, D., and Gough, N.M. 1994. Leukemia inhibitory factor and interleukin- 6 are expressed at very low levels in the normal adult mouse and are induced by inflammation. Cytokine 6: 300-309.

Bruce, A.J., Boling, W., Kindy, M.S., Peschon, J., Kraemer, P.J., Carpenter, M.K., Holtsberg, F.W., and Mattson, M.P. 1996. Altered neuronal and microglial responses to excitotoxic and ischemic brain injury in mice lacking TNF receptors. Nat. Med. 2: 788-794.

Castren, E., Pitkanen, M., Sirvio, J., Parsadanian, A., Lindholm, D., Thoenen, H., and Riekkinen, P. 1993. The induction of LTP increases BDNF and NGF mRNA but decreases NT-3 mRNA in the dentate gyrus. NeuroReport 4: 895-898.

Chomczynski, P. and Sacchi, N. 1987. Single-step method of RNA isolation by acid guanidinium thiocyanate-phenol-chloroform extraction. Anal. Biochem. 162: 156-159.

Cunningham, A.J., Murray, C.A., O'Neill, L.A.J., Lynch, M.A., and O'Connor, J.J. 1996. Interleukin-1 $\beta$ (IL-1 $\beta$ ) and tumour necrosis factor (TNF) inhibit long-term potentiation in the rat dentate gyrus in vitro. Neurosci. Lett. 203: 17-20.

Dragunow, M., Beilharz, E., Mason, B., Lawlor, P., Abraham, W, and Gluckman, P. 1993. Brain-derived neurotrophic factor expression after long-term potentiation. Neurosci. Lett. 160: 232-236.

Fann, M.J. and Patterson, P.H. 1995. Activins as candidate cholinergic differentiation factors in vivo. Int. J. Devl. Neurosci. 13: 317-330.

Frey, U., Huang, Y.Y., and Kandel, E.R. 1993. Effects of cAMP simulate a late stage of LTP in hippocampal CA1 neurons. Science 260: 1661-1664

Gadient, R.A. and Otten, U.H. 1997. Interleukin-6 (IL-6) - a molecule with both beneficial and destructive potentials. Progr. Neurobiol. 52: 379-390.

Gahring, L.C., White, H.S., Skradski, S.L., Carlson, N.G., and Rogers, S.W. 1997. Interleukin-1 $\alpha$ in the brain is induced by audiogenic seizure. Neurobiol. Dis. 3: 263-269.

Inokuchi, K., Kato, A., Hiraia, K., Hishinuma, F., Inoue, M., and Ozawa, F. 1996. Increase in activin $\beta A$ mRNA in rat hippocampus during long-term potentiation. FEBS Lett. 382: 48-52.

Jankowsky, J.L. and Patterson, P.H. 2000. Cytokine and growth factor involvement in long-term potentiation. Mol. Cell. Neurosci. 14: 529-543.

- 1999. Differential regulation of cytokine expression following pilocarpine-induced seizure. Exp. Neurol. 159: 333-346.

Jankowsky, J.L., Derrick, B.E., and Patterson, P.H. 1999. Cytokine responses to hippocampal slice preparation, in vivo electrode insertion, and LTP induction. Soc. Neurosci. Abstr. 25: 785.

Kang, H. and Schuman, E.M. 1995. Long-lasting neurotrophin-induced enhancement of synaptic transmission in the adult hippocampus. Science 267: 1658-1662.

Katsuki, H., Nakai, S., Hirai, Y., Akaji, K., Kiso, Y., and Satoh, M. 1990. Interleukin-1 $\beta$ inhibits long-term potentiation in the CA3 region of mouse hippocampal slices. Eur. J. Pharmacol. 181: 323-326.

Kirov, S.A., Sorra, K.E., and Harris, K.M. 1999. Slices have more synapses than perfusion-fixed hippocampus from both young and mature rats. $J$. Neurosci. 19: 2876-2886.

Lai, M., Sirimanne, E., Williams, C.E., and Gluckman, P.D. 1996. Sequential patterns of inhibin subunit gene expression following hypoxic-ischemic injury in the rat brain. Neuroscience 70: 1013-1024.

Li, A.-J., Katafuchi, T., Oda, S., Hori, T., and Oomura, Y. 1997. Interleukin-6 inhibits long-term potentiation in rat hippocampal slices. Brain Res. 748: 30-38.

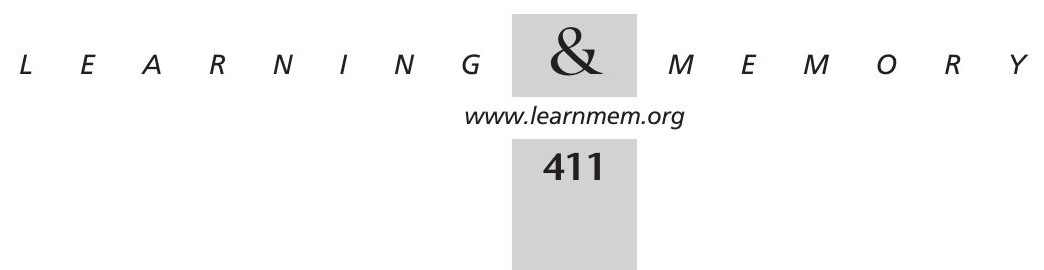


Loughlin, S.E., Fallon, J.H. (eds.). 1993. Neurotrophic Factors. Academic Press, Inc., San Diego, CA.

Mattson, M.P., Barger, S.W., Furukawa, K., Bruce, A.J., Wyss-Coray, T., Mark, R.J., and Mucke, L. 1997. Cellular signaling roles of TGF $\beta$, $\mathrm{TNF} \alpha$, and $\beta A P P$ in brain injury responses and Alzheimer's disease. Brain Res. Rev. 23: 47-61.

Minami, M., Kuraishi, Y., and Satoh, M. 1991. Effects of kainic acid on messenger RNA levels of IL-1 $\beta$, IL- 6 , TNF $\alpha$ and LIF in the rat brain. Biochem. Biophys. Res. Commun. 176: 593-598.

Mire-Sluis, A. and Thorpe, R. (eds.). 1998. Cytokines. Academic Press, San Diego, CA.

Morgan, T.E., Nichols, N.R., Pasinetti, G.M., and Finch, C.E. 1993. TGF- $\beta 1$ mRNA increases in macrophage/microglial cells of the hippocampus in response to deafferentation and kainic acid-induced neurodegeneration. Exp. Neurol. 120: 291-301.

Murphy, M., Dutton, R., Kolbar, S., Cheema, S., and Bartlett, P. 1997. Cytokines which signal through the LIF receptor and their actions in the nervous system. Progr. Neurobiol. 52: 355-378.

Murray, C.A. and Lynch, M.A. 1998. Evidence that increased hippocampal expression of the cytokine interleukin- $1 \beta$ is a common trigger for ageand stress-induced impairments in long-term potentiation. J. Neurosci. 18: 2974-2981.

Patterson, P.H. 1995. Neuronal growth and differentiation factors and synaptic plasticity. In: Psychopharmacology: The fourth generation of progress (eds. F.E. Bloom and D.J. Kupfer), pp. 619-629. Raven Press, Ltd., New York.

Patterson, P.H. and Fann, M.J. 1992. Further studies of the distribution of CDF/LIF mRNA. Ciba Foundation Symposium 167: 125-140.

Patterson, S.L., Grover, L.M., Schwartzkroin, P.A., and Bothwell, M. 1992. Neurotrophin expression in rat hippocampal slices: A stimulus paradigm inducing LTP in CA1 evokes increases in BDNF and NT-3 mRNAs. Neuron 9: 1081-1088.

Paxinos, G. and Watson, C. 1982. Stereotaxic Atlas of the Rat Brain. Academic Press, New York, NY.

Pitossi, F.J. and Besedovsky, H.O. 1996. A multispecific internal (pRat6) for the analysis of rat cytokine mRNA levels by quantitative RT-PCR. Eur. Cytokine Netw. 7: 377-379.

Racine, R.J. 1972. Modification of seizure activity by electrical stimulation: II. Motor seizure. Electroenceph. Clin. Neurophys. 32: 281-294.
Rawlins, J.N.P. and Green, K.F. 1977. Lamellar organization in the rat hippocampus. Exp. Brain Res. 28: 335-344.

Schneider, H., Pitossi, F., Balschun, D., Wagner, A., Del Rey, A., and Besedovsky, H.O. 1998. A neuromodulatory role of interleukin-1 $\beta$ in the hippocampus. Proc. Natl. Acad. Sci. 95: 7778-7783.

Sei, Y., Vitkovic, L., and Yokoyama, M.M. 1995. Cytokines in the central nervous system: Regulatory roles in neuronal function, cell death and repair. Neuroimmunomodulation 2: 121-133.

Silver, R., Silverman, A.-J., Vitkovic, L., and Lederhendler, I.I. 1996. Mast cells in the brain: Evidence and functional significance. Trends Neurosci. 19: 25-31.

Tretter, Y.P., Munz, B., Hubner, G., Bruggencate, G., Werner, S., and Alzheimer, C. 1996. Strong induction of activin expression after hippocampal lesion. NeuroReport 7: 1819-1823.

Turrigiano, G.G. 1999. Homeostatic plasticity in neuronal networks: The more things change, the more they stay the same. Trends Neurosci. 22: 221-227.

Turski, W.A., Cavalheiro, E.A., Schwarz, M., Czuczwas, S.J., Kleinrok, Z., and Turski, L. 1983. Limbic seizures produced by pilocarpine in rats: Behavioral, electroencephalographic and neuropathological study. Behav. Brain Res. 9: 315-335.

Vernadakis, A. 1996. Glia-neuron intercommunications and synaptic plasticity. Progr. Neurobiol. 49: 185-214

Yamamori, T., Fukada, K., Aebersold, R., Korsching, S., Fann, M.J., and Patterson, P.H. 1989. The cholinergic neuronal differentiation factor from heart cells is identical to leukemia inhibitory factor. Science 246: 1412-1416.

Yang, M.-F., Chien, C.-L., and Lu, K.-S. 1999. Morphological, immunohistochemical and quantitative studies of murine brain mast cells after mating. Brain Res. 846: 30-39.

Zaheer, A., Zhong, W.X., Uc, E.Y., Moser, D.R., and Lim, R. 1995. Expression of messenger-RNAs of multiple growth factors and receptors by astrocytes and glioma cells - detection with reverse transcription-polymerase chain reaction. Cell. Mol. Neurobiol. 15: 221-237.

Received April 17, 2000; accepted in revised form August 25, 2000.

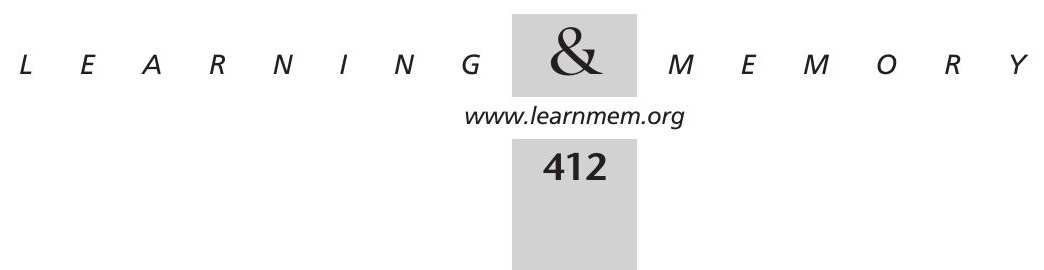




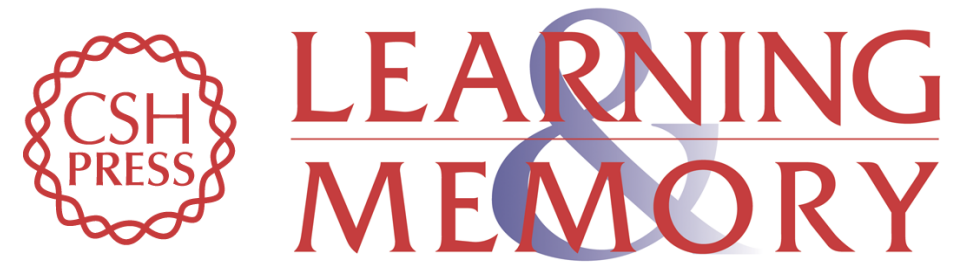

\section{Cytokine Responses to LTP Induction in the Rat Hippocampus: A Comparison of In Vitro and In Vivo Techniques}

Joanna L. Jankowsky, Brian E. Derrick and Paul H. Patterson

Learn. Mem. 2000, 7:

Access the most recent version at doi:10.1101//m.32600

References This article cites 46 articles, 7 of which can be accessed free at: http://learnmem.cshlp.org/content/7/6/400.full.html\#ref-list-1

License

Email Alerting Receive free email alerts when new articles cite this article - sign up in the box at the Service top right corner of the article or click here. 